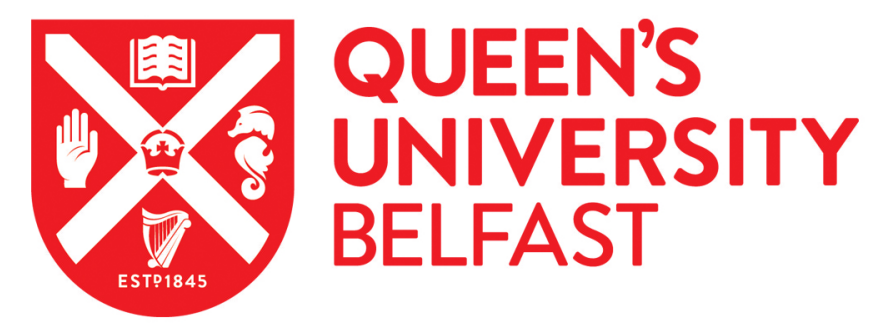

\title{
Increasing fruit and vegetable intake has no effect on retinal vessel caliber in adults at high risk of developing cardiovascular disease
}

\author{
McEvoy, C. T., Wallace, I. R., Hamill, L. L., Neville, C. E., Hunter, S. J., Patterson, C. C., Woodside, J. V., \\ Chakravarthy, U., Young, I. S., \& McKinley, M. C. (2016). Increasing fruit and vegetable intake has no effect on \\ retinal vessel caliber in adults at high risk of developing cardiovascular disease. Nutrition, Metabolism, and \\ Cardiovascular Diseases, 26(4), 318-25. https://doi.org/10.1016/j.numecd.2015.10.010
}

Published in:

Nutrition, Metabolism, and Cardiovascular Diseases

\section{Document Version:}

Peer reviewed version

Queen's University Belfast - Research Portal:

Link to publication record in Queen's University Belfast Research Portal

\begin{abstract}
Publisher rights
Copyright 2015 The Italian Society of Diabetology, the Italian Society for the Study of Atherosclerosis, the Italian Society of Human Nutrition, and the Department of Clinical Medicine and Surgery, Federico II University. Published by Elsevier B.V. All rights reserved.

This manuscript version is made available under the CC-BY-NC-ND 4.0 license http://creativecommons.org/licenses/by-nc-nd/4.0/ which permits distribution and reproduction for non-commercial purposes, provided the author and source are cited.
\end{abstract}

\section{General rights}

Copyright for the publications made accessible via the Queen's University Belfast Research Portal is retained by the author(s) and / or other copyright owners and it is a condition of accessing these publications that users recognise and abide by the legal requirements associated with these rights.

Take down policy

The Research Portal is Queen's institutional repository that provides access to Queen's research output. Every effort has been made to ensure that content in the Research Portal does not infringe any person's rights, or applicable UK laws. If you discover content in the Research Portal that you believe breaches copyright or violates any law, please contact openaccess@qub.ac.uk. 
Increasing fruit and vegetable intake has no effect on retinal vessel caliber in adults at high risk of developing cardiovascular disease.

McEvoy CT ${ }^{\mathrm{a}}$, Wallace IR ${ }^{\mathrm{a}}$, Hamill LL ${ }^{\mathrm{a}}$, Neville $\mathrm{CE}^{\mathrm{a}}$, Hunter SJ ${ }^{\mathrm{b}}$, Patterson $\mathrm{CC}^{\mathrm{a}}$, Woodside $\mathrm{JV}^{\mathrm{a}}$, Chakravarthy $\mathrm{U}^{\mathrm{c}}$, Young IS ${ }^{\mathrm{a}}$, McKinley MC ${ }^{\mathrm{a},{ }^{*}}$

${ }^{a}$ Centre for Public Health, Queen's University Belfast, Northern Ireland.

${ }^{\mathrm{b}}$ Regional Centre for Endocrinology \& Diabetes, Belfast Health and Social Care Trust, Northern Ireland.

'Centre for Experimental Medicine, Queen's University Belfast, Northern Ireland.

*Corresponding author: Dr Michelle C McKinley, Centre for Public Health, Queen's University Belfast, Institute of Clinical Science B, Grosvenor Road, Belfast, BT12 6BJ, UK Tel: +44 (0)28 9063 2685; Fax: +44 (0)28 9023 5900; Email: m.mckinley@qub.ac.uk.

Clinical Trial registration: ClinicalTrials.gov NCT00874341; $1^{\text {st }}$ April 2009

Key words: Retinal vessel caliber; Fruit; Vegetables 


\section{Abstract}

Background and aim: Retinal vessel abnormalities are associated with cardiovascular disease (CVD) risk. To date, there are no trials investigating the effect of dietary factors on the retinal microvasculature. This study examined the dose response effect of fruit and vegetable (FV) intake on retinal vessel caliber in overweight adults at high CVD risk. Methods and results: Following a 4 week washout period, participants were randomized to consume either 2 or 4 or 7 portions of FV daily for 12 weeks. Retinal vessel caliber was measured at baseline and post-intervention. A total of 62 participants completed the study. Self-reported FV intake indicated good compliance with the intervention, with serum concentrations of zeaxanthin and lutein increasing significantly across the groups in a dosedependent manner $(P$ for trend $<0.05)$. There were no significant changes in body composition, 24-hour ambulatory blood pressure or fasting blood lipid profiles in response to the FV intervention. Increasing age was a significant determinant of wider retinal venules ( $P$ $=0.004$ ) whereas baseline systolic blood pressure was a significant determinant of narrower retinal arterioles $(P=0.03)$. Overall, there was no evidence of any short-term dose-response effect of FV intake on retinal vessel caliber (CRAE $(P=0.92)$ or CRVE $(P=0.42)$ ). Conclusions: This study demonstrated no effect of increasing FV intake on retinal vessel caliber in overweight adults at high risk of developing primary CVD. Clinical Trial registration: NCT00874341. 


\section{Introduction}

Cardiovascular disease (CVD) is the leading cause of death worldwide [1] and diet is known to play a pathogenic role in CVD development [2]. Fruit and vegetables (FV) represent the most botanically diverse food group with potential bioactive properties believed to offer vascular protection [3]. A minimum intake of $400 \mathrm{~g} F V$ per day (equivalent to 5 portions excluding potatoes) is recommended as an effective strategy for primary CVD prevention [4], which is supported by observational data [5] and confirmed by meta-analyses [6, 7]. While an effect of increased FV intake on CVD events has yet to be demonstrated, there is some evidence of a beneficial effect of increased FV intake on known markers of CVD risk [2] including vascular function [8].

Microvascular disease has been implicated in the early development of CVD and may be reversible [9]. Therefore, strategies to improve microvascular health are of major public interest for CVD prevention. A recent clinical intervention study in hypertensive adults demonstrated a significant improvement in microvascular function with increasing FV intake in a dose-response manner [8]. In this study, microvascular function was determined by a trained clinician using a high risk, invasive procedure involving brachial artery cannulation and assessment of forearm blood flow response to administration of acetylcholine.

The retinal microvasculature is the only vascular bed that can be directly visualized in vivo and may provide a non-invasive, surrogate method of assessing microvascular health. It is possible that changes in the retinal microvasculature reflect structural or functional changes in the overall systemic microcirculation. Observational studies have linked structural changes in the retinal vessels with established CVD risk factors, including hypertension, obesity and diabetes [10-12]. Furthermore, meta-analyses of prospective studies have reported significant associations between narrower retinal arterioles and wider retinal venules and increased coronary heart disease risk [13] and stroke risk [14]. Intriguingly, small clinical trials have demonstrated retinal vessel abnormality regression with low density lipoprotein apheresis in hypercholesterolaemic patients $[15,16]$ and differential effects of antihypertensive medications on the retinal vessels [17]. These data suggest that the retinal microvasculature is dynamic and can respond favourably to drug treatments.

Diet may also influence the retinal vessel caliber but study data are limited to cross-sectional observations. These studies have reported inverse relationships between retinal vessel abnormalities and some dietary constituents such as dietary fibre [18], fish [19] and dairy intake [20]. However, adherence to a healthy or unhealthy derived dietary pattern was not found to be related to retinal vessel caliber measurement in European older adults [21]. To 
our knowledge, there are no published intervention studies examining the effect of dietary constituents on retinal vessel diameter.

In this study, we examined the dose-response effect of a randomized short-term FV intake intervention on retinal vessel caliber in healthy, overweight individuals at high CVD risk.

\section{Methods}

\section{Study population}

Details of this dietary intervention trial have been reported elsewhere [22]. Adults without existing diabetes mellitus and CVD but $\geq 20 \%$ CVD risk over the next 10 years as defined by Joint British Societies' Guidelines on prevention of CVD in clinical practice [23] and with a Body Mass Index (BMI) $\geq 27$ and $\leq 35 \mathrm{~kg} / \mathrm{m}^{2}$ and low habitual FV consumption ( $\leq 2$ portions per day) were recruited from medical outpatient clinics and from the general public.

\section{Study design}

This was a parallel group randomized controlled trial. The Office for Research Ethics Committees Northern Ireland provided ethical approval for this trial according to the principles of the Helsinki Declaration. The study protocol was registered on ClinicalTrials.gov (NCT00874341) and outcomes were stipulated a priori. All participants provided written informed consent for the study.

Following a 4 week washout period, where FV intake was limited to no more than 2 portions per day $(1$ portion $=80 \mathrm{~g}$ ), participants were block randomized using a computer generated number sequence to one of the three intervention groups: 2 or 4 or 7 portions of FV per day for the next 12 consecutive weeks. Participants were instructed to keep body weight, physical activity and other lifestyle behaviours unchanged during the intervention period.

Several strategies were used to maximize compliance with the FV intervention. Written dietary advice corresponding to the allocated FV group was provided to all participants at baseline. Personalized dietetic advice to increase FV intake and encourage FV variety was also given to participants allocated to the 4- and 7-portion groups. All participants received a weekly FV delivery for the duration of the intervention and were telephoned on a weekly basis to monitor compliance and body weight and discuss any individual difficulties with adherence to the study protocol.

\section{Study assessments}


Participants attended a dedicated research facility in the morning following an overnight fast for study measurements performed at baseline (week 4) and repeated at the end of the intervention (week 16). Demographic and lifestyle data were collected via self-administered questionnaires. Anthropometrics including height, weight, waist and hip circumference were measured and body mass index $(\mathrm{BMI})\left(\mathrm{kg} / \mathrm{m}^{2}\right)$ was calculated as weight $(\mathrm{kg}) /$ height $(\mathrm{m})^{2}$. Total body fat (\%) was assessed using whole body Dual Energy X-ray Absorptiometry (DXA) (GE Medical Systems, Madison, WI). Blood pressure was measured using 24 hour ambulatory blood pressure (Meditech ABPM-04 P.M.S. (Instruments) Ltd, Bershire, UK). A fasting venous blood sample was collected, processed and stored within 2 hours of collection at $-80^{\circ} \mathrm{C}$ for analysis.

Retinal photography was performed by a trained researcher using a Topcon TRC 50 EX (Topcon, Tokyo, Japan) digital camera according to a standardized protocol [21]. A color stereoscopic fundus image of visual field one (centered on the optic disc); using a field of $35^{\circ}$ at a flash setting of $50 \mathrm{~mW}$ was captured for each eye after dilation. One trained researcher measured the internal retinal vessel diameters from the obtained right eye fundus image using a validated semi-automated software program and measurement protocol (IVAN, Wisconsin, USA) as used in previous studies [10-14, 21]. In brief, all retinal vessels > $25 \mu \mathrm{m}$ coursing through a specified area (0.5-1.0 disc diameter surrounding the optic disc zone) were tracked by the software using microdensitometry, and were then identified as either arterioles or venules by the researcher. The largest identified arterioles and venules were measured in micrometers $(\mu \mathrm{m})$. The 6 largest arteriole and 6 largest venule diameter measurements were combined in an iterative process using validated formulae [24] to produce summary indices representing the mean retinal arteriole caliber (CRAE) and mean retinal venule caliber (CRVE).

\section{Dietary compliance}

Compliance with the intervention was determined using self-reported dietary data collected using a 4-day food record. Reported FV portions consumed by each participant were hand counted independently by two researchers from the 4-day food records and any discrepancies were assessed and resolved with input from a third researcher. Self-reported FV intake was validated using a panel of nutritional biomarkers as outlined below.

\section{Laboratory analysis}


Serum concentrations of carotenoid vitamins (lutein, zeaxanthin, $\beta$-cryptoxanthin, $\alpha$ carotene, $\beta$-carotene and lycopene) were measured by high performance liquid chromatography with diode array detection [22]. Fasting serum lipid profile (total cholesterol, high density lipoprotein (HDL) and triglycerides) were measured using enzymatic assays on an ILab-600 biochemical analyser (Instrumentation Laboratories/Werfern, Warrington). Low density lipoprotein (LDL) cholesterol was calculated using a standard Friedewald formula. Plasma glucose (FPG) was measured using an automated glucose oxidase method using a Beckman Glucose Analyser 2.

\section{Statistical analysis}

A power calculation was performed based on the primary endpoint of the trial; insulin resistance measured using a euglycaemic-hyperinsulinaemic clamp technique which has been reported [22]. In this study, subgroup analyses were carried out for participants with valid retinal vessel measurements pre- and post-intervention. Descriptive statistics (means, standard deviations and proportions) were used to summarize baseline characteristics of the sample according to FV allocation group. Variables that were not normally distributed were log transformed prior to statistical analyses and summarized using the geometric mean and interquartile range (IQR). Paired t-test analyses were used to determine within group changes between baseline and post-intervention measurements. One-way analysis of variance with linear trend test was used to examine differences in mean change (i.e. postintervention value - pre-intervention value) for measurement variables between groups. Analysis of covariance (general linear model) was used to compare retinal vessel caliber measurement in response to the FV intervention adjusting for baseline covariates. The covariates included age (years), systolic blood pressure $(\mathrm{mmHg})$, smoking status (yes/no) and gender (male/female). Significance was defined as a $P$ value $\leq 0.05$. All statistical analyses were carried out using SPSS version 22.0 (IBM Corp, Armonk, NY).

\section{Results}

A total of 105 participants agreed to take part in this study. During the initial 4 week wash out period, 13 (12.4\%) withdrew from the study (see Supplemental Figure 1). A total of 92 participants proceeded to the intervention phase of the study (week 4-16) and 89 participants completed the study protocol. For this analysis, valid retinal vessel caliber 
measurements and dietary data were available for 62 study participants at baseline and post-intervention (see Supplemental Figure 1 for details).

Baseline characteristics of the 62 participants (41 male) according to FV allocation are shown in Table 1. For the study population the mean (SD) CRAE was 158.2 (14.3) $\mu \mathrm{m}$ and mean (SD) CRVE was 235.2 (21.9) $\mu \mathrm{m}$. Overall, there were no significant differences in any of the measured variables between the three FV groups at baseline.

Change in self-reported FV intake and measured micronutrient status indicated good compliance with the intervention. Self-reported FV did not significantly change from baseline in the 2 portions/day group, while reported mean FV intake increased to 3.7 and 7.2 portions/day within the 4 and 7 portion/day groups respectively $(P<0.0001)$. In addition, there were significant between group changes in micronutrient concentration in response to the intervention similar to that previously reported [22]. In this sub-study, a significant doseresponse effect of increasing FV intake on lutein $\left(P_{\text {Trend }}<0.0001\right)$ and zeaxanthin status $\left(P_{\text {Trend }}=0.009\right)$ was observed.

There was no significant change in body weight, total body fat, or markers of CVD risk (ambulatory blood pressure variables and serum lipid profiles) between the FV groups as a result of the intervention as shown in Table 2.

Despite good compliance with the intervention, increasing FV intake had no significant effect on CRAE or CRVE measurement changes as shown in Table 3. Mean changes in CRAE and CRVE measurements were adjusted for baseline covariates (age, gender, smoking status and systolic blood pressure) but still showed no evidence of any effect of increasing FV intake on retinal vessel caliber.

In the overall study population, systolic blood pressure was a significant predictor of retinal arteriole caliber post intervention $(0.4 \mu \mathrm{m}$ narrowing per $1 \mathrm{mmHg} ; P=0.03)$ and age was a significant predictor of retinal venule caliber post intervention $(0.6 \mu \mathrm{m}$ widening in venule diameter per year; $P=0.004$ ) as shown in Table 4. There were no further significant associations between retinal vessel caliber measurements and other measured clinical variables.

\section{Discussion}

Putative mechanisms for a beneficial role of $\mathrm{FV}$ intake for vascular health include an increased antioxidant capacity of the diet which can inhibit oxidative stress, reduce 
endothelial damage and prevent atherosclerosis [3]. To our knowledge, this is the first dietary intervention study to test the effect of increasing FV intake on retinal vessel diameter measurement. While self-reported FV intake indicated good compliance with the FV intervention and micronutrient status improved in response to the increasing FV intake, there was no beneficial effect of increased FV intake on retinal vessel caliber in overweight adults, at high risk of developing CVD.

In contrast a recent clinical intervention study involving hypertensive adults, found a $6 \%$ improvement in microvascular function with each additional FV portion per day [8]. The disparity in findings may be explained by differences in study population, study design and methods of examining the microcirculation. In the latter study, microvascular function was determined using an established method involving brachial artery cannulation and measuring forearm blood flow response to acetylcholine administration: a method shown to be valid, reliable and to have prognostic significance in predicting CVD events [25]. Quantification of the retinal vessel caliber is a relatively novel method to determine in vivo microvascular structure rather than vessel function. While retinal vascular abnormalities are contended to parallel changes in other microvascular beds the evidence to support this assertion is limited at present [26]. Further research to determine the extent to which the retinal microvasculature is a surrogate for microvascular beds in the coronary circulation will strengthen the rationale for employing this non-invasive method in clinical studies investigating vascular health as an end-point [26].

Major CVD risk factors such as elevated blood pressure and obesity are known to induce similar phenotypic (pro-oxidative, pro-inflammatory, pro-thrombogenic) changes in all vascular beds including the microcirculation [27] and these factors have also been linked to morphological alteration of the retinal vessels $[10,11]$. It is possible that vascular reactivity is mediated, in part, by changes in arterial blood pressure. McCall et al [8] reported a nonsignificant trend in systolic blood pressure reduction with increasing FV intake. In the present study, no significant change in blood pressure measurement was observed in response to the FV intervention which may have contributed to the null findings in relation to retinal vessel caliber.

The impact of body weight/composition change on retinal vessel caliber is not yet known. In this study, participants were instructed to keep body weight stable during the intervention in order to test the specific effect of increasing FV intake on retinal vessel caliber while minimizing potential confounding associated with change in body weight or composition. Our results indicated that measured body weight and total body fat did not alter significantly in 
response to increasing FV intake, and therefore cannot be considered a confounding factor in the study.

While the correlation of retinal vessel caliber with other microvascular systems is not fully explained at the present time, measurement of the retinal vessels may have relevance in terms of CVD risk stratification. Epidemiological studies have shown that narrower retinal arterioles are associated with CVD in women and are predictive of future hypertension development $[13,28]$. Narrow retinal arterioles are most strongly associated with past and present blood pressure levels. We found that systolic blood pressure was a significant determinant of narrower arterioles in our middle-aged population. Each $1 \mathrm{mmHg}$ increase in systolic blood pressure was associated with a $0.4 \mu \mathrm{m}$ narrowing in arteriole diameter. The magnitude of this association is similar to that reported in other prospective studies in adults; each $10 \mathrm{mmHg}$ increase in mean arterial BP was associated with a $1.1 \mu \mathrm{m}$ decrease in CRAE [29].

Wider venules are most strongly associated with increased risk of stroke in both men and women and may be predictive of future development of type 2 diabetes and also retinopathy in adults with existing diabetes [14, 28]. Systemic determinants of wider venules appear to be obesity, blood glucose levels and smoking status. We did not find any relationship between BMI and retinal venule caliber which was not surprising considering all study participants were selected as being overweight/clinically obese with evidence of abdominal obesity. We also did not observe significant associations between retinal venule caliber and smoking status or fasting glucose concentrations; however it is possible that the small number of current smokers and participants with impaired glucose level in this study attenuated any potential associations. Age was the most important determinant of retinal venule caliber in our middle-aged population with each 1 year increase in age associated with an approximate $0.6 \mu \mathrm{m}$ widening in venule diameter.

This study has several strengths including the randomized controlled study design and high compliance with the FV intervention. In addition, one trained researcher used a validated measurement and analysis protocol to objectively measure retinal vessel caliber as employed in previous studies [10-14, 21]. Several potential limitations of this study should be mentioned. The possibility of measurement error exists as there are several potential sources of variation in the quantification of retinal vessel caliber including potential confounding effect of refractive and magnification error. However, reliability of this method to assess retinal vessels has been previously reported as high, with inter-grader weighted kappa of 0.85 and 0.90 and intra-grader weighted kappa between 0.80 and 0.93 for arteriolar and venular caliber measurements respectively [26]. Furthermore, coefficients of 
variation of repeated measures of CRAE and CRVE are reported as less than 2\% [30]. Unfortunately, we were unable to determine intra-grader variability due to time and cost limitations of the study. A second limitation of this study is that retinal vessel caliber was a secondary end-point outcome measurement and an optional component of an already demanding study protocol. Therefore, the small sample size may limit the study findings. However, a retrospective power calculation based on the variability of CRAE and CRVE changes from the low (2 portions/day) FV group (SD 14.5 and $16.6 \mu \mathrm{m}$, respectively) suggests that the current study sample size had in excess of $90 \%$ power to detect as statistically significant $(P=0.05$, two-tailed test) a difference of $10 \%$ in retinal vessel caliber measurements between two groups.

In conclusion, increased FV intake improved micronutrient status but had no significant effect on retinal vessel caliber in adults at high risk of developing CVD. This study supports the continued promotion of $\mathrm{FV}$ on the basis of improving micronutrient status but not in relation to retinal vessel caliber measurement.

\section{Acknowledgements}

The authors thank Mr Vittorio Silvestri, Dr Sarah Gilchrist and Mr Cyril McMaster for their technical expertise and advice.

\section{References}

[1] World Health Organisation (WHO).Prevention of cardiovascular disease. Guidelines for assessment and management of cardiovascular risk. 2007. Geneva: WHO.

[2] Hartley L, Igbinedion E, Holmes J et al. Increased consumption of fruit and vegetables for the primary prevention of cardiovascular diseases. Cochrane Database Syst Rev. 2013;6:CD009874. doi: 10.1002/14651858.CD009874.pub2.

[3] Lampe JW. Health effects of vegetables and fruit: assessing mechanisms of action in human experimental studies. Am J Clin Nutr. 1999; 70(3 Suppl):475S-490S.

[4] World Health Organisation (WHO). Diet, nutrition and the prevention of chronic diseases: Report of a joint WHO/FAO Expert Consultation. Technical Report Series No. 916. 2003. Geneva: WHO.

[5] Boeing $\mathrm{H}$, Bechthold A, Bub A et al. Critical review: vegetables and fruit in the prevention of chronic diseases. Eur J Nutr. 2012;51:637-663. doi: 10.1007/s00394-012-0380-y. 
[6] Dauchet L, Amouyel P, Hercberg S et al. Fruit and vegetable consumption and risk of coronary heart disease: a meta-analysis of cohort studies. J Nutr. 2006;136(10):2588-2593.

[7] He FJ, Nowson CA, Lucas $M$ et al. Increased consumption of fruit and vegetables is related to a reduced risk of coronary heart disease: meta-analysis of cohort studies. J Hum Hypertens. 2007;21(9):717-728.

[8] McCall DO, McGartland CP, McKinley MC et al. Dietary intake of fruits and vegetables improves microvascular function in hypertensive subjects in a dose-dependent manner. Circulation 2009;119(16):2153-2160. doi: 10.1161/CIRCULATIONAHA.108.831297.

[9] Leung DY, Leung M. Non-invasive/invasive imaging: significance and assessment of coronary microvascular dysfunction. Heart 2011;97(7):587-595. doi: 10.1136/hrt.2009.183327.

[10] Boillot A, Zoungas S, Mitchell $P$ et al. Obesity and the microvasculature: a systematic review and meta-analysis. PLoSOne. 2013;8(2):e52708. doi: 10.1371/journal.pone.0052708.

[11] Ding J, Wai KL, McGeechan K et al. Retinal vascular caliber and the development of hypertension: a meta-analysis of individual participant data. J Hypertens. 2014;32(2):207-15. doi: 10.1097/HJH.0b013e32836586f4.

[12] Ikram MK, Janssen JA, Roos AM et al. Retinal vessel diameters and risk of impaired fasting glucose or diabetes: the Rotterdam study. Diabetes 2006;55(2):506-510.

[13] McGeechan K, Liew G, Macaskill P et al. Meta-analysis: retinal vessel caliber and risk for coronary heart disease. Ann Intern Med. 2009;151(6):404-413.

[14] McGeechan K, Liew G, Macaskill P et al. Prediction of incident stroke events based on retinal vessel caliber: a systematic review and individual-participant meta-analysis. Am J Epidemiol. 2009;170(11):1323-1332. doi: 10.1093/aje/kwp306.

[15] Reimann M, Prieur S, Lippold B et al. Retinal vessel analysis in hypercholesterolemic patients before and after LDL apheresis. Atheroscler Suppl. 2009;10(5):39-43. doi: 10.1016/S1567-5688(09)71808-2.

[16] Terai N, Julius U, Haustein $M$ et al. The effect of low-density lipoprotein apheresis on ocular microcirculation in patients with hypercholesterolaemia: a pilot study. Br J Ophthalmol 2011;95(3):401-404. doi: 10.1136/bjo.2010.180901.

[17] Thom S, Stettler C, Stanton A et al. Differential effects of antihypertensive treatment on the retinal microcirculation: an anglo-scandinavian cardiac outcomes trial substudy. Hypertension 2009;54(2):405-408. doi: 10.1161/HYPERTENSIONAHA.109.133819. 
[18] Kan H, Stevens J, Heiss G et al. Dietary fiber intake and retinal vascular caliber in the Atherosclerosis Risk in Communities Study. Am J Clin Nutr 2007;86(6):1626-1632.

[19] Kaushik S, Wang JJ, Flood V et al. Frequency of fish consumption, retinal microvascular signs and vascular mortality. Microcirculation 2008;15(1):27-36.

[20] Gopinath B, Flood VM, Burlutsky G et al. Dairy food consumption, blood pressure and retinal microcirculation in adolescents. Nutr Metab Cardiovasc Dis. 2014;24(11):1221-7. doi: 10.1016/j.numecd.2014.05.014.

[21] McEvoy CT, Cardwell CR, Chakravarthy U et al. A posteriori-derived dietary patterns and retinal vessel caliber in an elderly population. Invest Ophthalmol Vis Sci. 2013;54(2):1337-44. doi: 10.1167/iovs.12-11065.

[22] Wallace IR, McEvoy CT, Hunter SJ et al. Dose-response effect of fruit and vegetables on insulin resistance in people at high risk of cardiovascular disease: a randomized controlled trial. Diabetes Care. 2013;36(12):3888-96. doi: 10.2337/dc13-0718

[23] Wood DA.JBS 2: Joint British Societies' guidelines on prevention of cardiovascular disease in clinical practice. Heart 2005;91:v1-v52.

[24] Knudtson MD, Lee KE, Hubbard LD et al. Revised formulas for summarizing retinal vessel diameters. Curr Eye Res 2003;27(3):143-149.

[25] McCall DO, McKinley MC, Noad R et al. The assessment of vascular function during dietary intervention trials in human subjects. $\mathrm{Br} J$ Nutr 2011;106(7):981-994. doi: 10.1017/S0007114511002996.

[26] Liew G, Wang JJ, Mitchell P, Wong TY. Retinal vascular imaging: a new tool in microvascular disease research. Circ Cardiovasc Imaging 2008;1(2):156-61. doi: 10.1161/CIRCIMAGING.108.784876.

[27] Granger DN, Rodrigues SF, Yildirim A et al. Microvascular responses to cardiovascular risk factors. Microcirculation 2010;17(3): 192-205. doi: 10.1111/j.1549-8719.2009.00015.x.

[28] Nguyen TT, Wang JJ, Wong TY. Retinal vascular changes in pre-diabetes and prehypertension: new findings and their research and clinical implications. Diabetes Care 2007;30(10):2708-2715.

[29] Ikram MK, de Jong FJ, Vingerling JR et al. Are retinal arteriolar or venular diameters associated with markers for cardiovascular disorders? The Rotterdam Study. Invest Ophthalmol Vis Sci 2004;45(7):2129-2134. 
[30] De Boever P, Louwies T, Provost E et al. Fundus photography as a convenient tool to study microvascular responses to cardiovascular disease risk factors in epidemiological studies. J Vis Exp 2014;22(92):e51904. doi: 10.3791/51904. 
Table 1: Baseline characteristics of study participants $(n=62)$ according to Fruit and vegetable (FV) group allocation.

\begin{tabular}{|c|c|c|c|c|}
\hline & $\begin{array}{l}2 \text { portions } \\
\text { FV/day } \\
(\mathrm{n}=20)\end{array}$ & $\begin{array}{l}4 \text { portions } \\
\text { FV/day } \\
(n=20)\end{array}$ & $\begin{array}{l}7 \text { portions } \\
\text { FV/day } \\
\text { ( } n=22)\end{array}$ & $\begin{array}{l}\text { Between group } \\
\text { P- value }^{\mathrm{a}, \mathrm{b}}\end{array}$ \\
\hline Age (years) & $56.6(5.2)$ & $58.2(5.3)$ & $55.5(7.7)$ & 0.38 \\
\hline Males, $\mathrm{n}(\%)^{\mathrm{b}}$ & $11(55)$ & $14(70)$ & $16(73)$ & 0.43 \\
\hline Current smokers, $\mathrm{n}(\%)^{\mathrm{b}}$ & $2(10)$ & $4(20)$ & $3(14)$ & 0.66 \\
\hline Weight (kg) & $87.3(12.4)$ & $87.3(9.8)$ & $87.5(9.1)$ & 0.99 \\
\hline BMI $\left(\mathrm{kg} / \mathrm{m}^{2}\right)$ & $31.4(2.5)$ & $30.9(2.5)$ & $30.2(1.8)$ & 0.25 \\
\hline Waist circumference (cm) & $104.2(8.6)$ & $104.9(7.4)$ & $102.6(6.4)$ & 0.61 \\
\hline Waist to hip ratio & $0.96(0.08)$ & $0.99(0.06)$ & $0.96(0.05)$ & 0.34 \\
\hline Body fat (\%) & $40.0(7.3)$ & $36.8(6.1)$ & $37.0(6.6)$ & 0.24 \\
\hline Systolic blood pressure ( $\mathrm{mmHg}$ ) & $127.8(11.0)$ & $126.0(10.7)$ & $129.4(9.9)$ & 0.57 \\
\hline Diastolic blood pressure $(\mathrm{mmHg})$ & $75.1(7.9)$ & $76.6(6.6)$ & $77.5(6.6)$ & 0.56 \\
\hline Total cholesterol (mmol/L) & $5.51(1.02)$ & $5.49(1.17)$ & $5.60(1.19)$ & 0.95 \\
\hline LDL cholesterol (mmol/L) & $3.35(1.00)$ & $3.29(1.06)$ & $3.51(1.07)$ & 0.78 \\
\hline HDL cholesterol (mmol/L) & $1.31(0.23)$ & $1.29(0.41)$ & $1.25(0.34)$ & 0.81 \\
\hline Triglyceride $(\mathrm{mmol} / \mathrm{L})^{\mathrm{c}}$ & $1.93(1.45,2.44)$ & $1.85(1.34,2.40)$ & $1.70(1.25,2.25)$ & 0.59 \\
\hline Total: HDL cholesterol ratioc & $4.19(3.36,4.85)$ & $4.32(3.83,5.30)$ & $4.53(3.51,5.78)$ & 0.62 \\
\hline Antihypertensive medications, $\mathrm{n}(\%)^{\mathrm{b}}$ & $7(35)$ & $7(35)$ & $6(27)$ & 0.82 \\
\hline Lipid lowering therapy, $n(\%)^{b}$ & $10(50)$ & $7(35)$ & $5(23)$ & 0.18 \\
\hline Fasting plasma glucose $(\mathrm{mmol} / \mathrm{L})^{\mathrm{d}}$ & $5.54(0.50)$ & $5.71(0.71)$ & $5.44(0.55)$ & 0.37 \\
\hline CRAE $(\mu \mathrm{m})$ & $158.9(12.6)$ & $160.7(15.5)$ & $155.3(14.6)$ & 0.46 \\
\hline CRVE $(\mu \mathrm{m})$ & $228.9(20.9)$ & $239.8(20.7)$ & $236.9(23.4)$ & 0.27 \\
\hline Fruit and vegetable intake (portions $\mathrm{e}^{\mathrm{e}}$ day) & $1.71(0.98)$ & $1.70(0.70)$ & $1.62(0.81)$ & 0.90 \\
\hline Fruit and vegetable intake (g/day) & $137(78)$ & $136(56)$ & $130(65)$ & 0.90 \\
\hline
\end{tabular}

aBetween group comparisons are made using one-way analysis of variance. ${ }^{\mathrm{b} B e t w e e n}$ group comparisons for categorical variables are made using Chi Square test with $2 \mathrm{df}$. 'Skewed variable logarithmically transformed for analysis and summarised as geometric mean (IQR). ${ }^{\mathrm{d} A v a i l a b l e}$ for 19, 20, 22 participants in the 2-, 4- and 7- portions/day group, respectively. 1 portion=80g. FV = Fruit and Vegetables; CRAE = Central Retinal Arteriole Equivalent; CRVE = Central Retinal Venule Equivalent. 
Table 2: Mean change in clinical measurements in response to intervention $(n=62)$, according to FV allocation.

\begin{tabular}{|c|c|c|c|c|c|c|c|c|c|c|c|}
\hline \multirow{2}{*}{ Variable measured ${ }^{a}$} & \multicolumn{3}{|c|}{2 portions FV/day $(n=20 \max )$} & \multicolumn{3}{|c|}{4 portions FV/day ( $n=20 \max )$} & \multicolumn{3}{|c|}{7 portions FV/day $(n=22 \max )$} & \multirow{2}{*}{$\begin{array}{l}\text { Between } \\
\text { group P } \\
\text { value }^{c}\end{array}$} & \multirow{2}{*}{$P_{\text {Trend }}{ }^{d}$} \\
\hline & Week 4 & Week 16 & $\begin{array}{l}\text { Change } \\
(95 \% \mathrm{Cl})\end{array}$ & Week 4 & Week 16 & $\begin{array}{l}\text { Change } \\
\text { (95\% Cl) }\end{array}$ & Week 4 & Week 16 & $\begin{array}{l}\text { Change } \\
(95 \% \mathrm{Cl})\end{array}$ & & \\
\hline Weight (kg) & $87.3(12.4)$ & $87.7(12.7)$ & $\begin{array}{c}\mathbf{0 . 4 9} \\
(-0.26,1.23)\end{array}$ & $87.3(9.8)$ & $87.7(10.1)$ & $\begin{array}{c}\mathbf{0 . 4 5} \\
(-0.28,1.17)\end{array}$ & $87.5(9.1)$ & $88.0(9.3)$ & $\begin{array}{c}\mathbf{0 . 5 3} \\
(-0.03,1.08)\end{array}$ & 0.98 & 0.92 \\
\hline Body Mass Index (kg/m²) & $31.4(2.5)$ & $31.6(2.6)$ & $\begin{array}{c}\mathbf{0 . 1 5} \\
(-0.10,0.40)\end{array}$ & $30.9(2.5)$ & $31.1(2.7)$ & $\begin{array}{c}\mathbf{0 . 1 6} \\
(-0.09,0.41)\end{array}$ & $30.2(1.8)$ & $30.4(1.8)$ & $\begin{array}{c}\mathbf{0 . 1 9} \\
(0.01,0.38)\end{array}$ & 0.97 & 0.80 \\
\hline $\begin{array}{l}\text { Waist circumference } \\
\text { (cm) }\end{array}$ & $104.2(8.6)$ & $104.9(8.3)$ & $\begin{array}{c}\mathbf{0 . 7 0} \\
(0.00,1.40)\end{array}$ & $104.4(7.3)$ & $105.1(7.3)$ & $\begin{array}{c}\mathbf{0 . 6 3} \\
(-0.53,1.80)\end{array}$ & $102.6(6.4)$ & $102.8(6.4)$ & $\begin{array}{c}\mathbf{0 . 1 8} \\
(-1.17,1.53)\end{array}$ & 0.75 & 0.49 \\
\hline Waist to hip ratio & $0.96(0.08)$ & $0.97(0.09)$ & $\begin{array}{c}\mathbf{0 . 0 0} \\
(-0.01,0.01)\end{array}$ & $0.98(0.06)$ & $0.98(0.06)$ & $\begin{array}{c}\mathbf{0 . 0 0} \\
(-0.01,0.01)\end{array}$ & $0.96(0.05)$ & $0.96(0.05)$ & $\begin{array}{c}\mathbf{0 . 0 0} \\
(-0.01,0.01)\end{array}$ & 0.42 & 0.25 \\
\hline Body Fat (\%) & $40.0(7.3)$ & $40.4(7.6)$ & $\begin{array}{c}\mathbf{0 . 4 3} \\
(-0.14,0.98)\end{array}$ & $36.9(6.3)$ & $37.0(6.5)$ & $\begin{array}{c}\mathbf{0 . 0 8} \\
(-0.62,0.79)\end{array}$ & $37.6(6.0)$ & $37.9(6.4)$ & $\begin{array}{c}\mathbf{0 . 2 9} \\
(-0.24,0.81)\end{array}$ & 0.71 & 0.74 \\
\hline $\begin{array}{l}\text { Systolic blood pressure } \\
(\mathrm{mmHg})\end{array}$ & $127.8(11.0)$ & $124.7(15.0)$ & $\begin{array}{c}-3.1 \\
(-9.0,2.8)\end{array}$ & $126.0(10.7)$ & $127.5(11.4)$ & $\begin{array}{c}1.5 \\
(-3.3,6.3)\end{array}$ & $130.4(9.1)$ & $127.1(9.0)$ & $\begin{array}{c}3.4 \\
(-6.94,0.24)\end{array}$ & 0.26 & 0.10 \\
\hline $\begin{array}{l}\text { Diastolic blood pressure } \\
(\mathrm{mmHg})\end{array}$ & $75.1(7.9)$ & $73.0(10.1)$ & $\begin{array}{c}2.1 \\
(-5.82,1.62)\end{array}$ & $76.6(6.5)$ & $77.1(9.0)$ & $\begin{array}{c}\mathbf{0 . 5} \\
(-2.9,3.8)\end{array}$ & $78.0(6.3)$ & $75.8(8.2)$ & $\begin{array}{c}-2.2 \\
(-5.2,0.8)\end{array}$ & 0.43 & 0.19 \\
\hline LDL cholesterol (mmol/L) & $3.35(1.00)$ & $3.58(1.10)$ & $\begin{array}{c}\mathbf{0 . 2 3} \\
(-0.09,0.55)\end{array}$ & $3.29(1.06)$ & $3.07(0.92)$ & $\begin{array}{c}-\mathbf{0 . 2 2} \\
(-0.54,0.09)\end{array}$ & $3.52(1.10)$ & $3.40(0.91)$ & $\begin{array}{c}\mathbf{- 0 . 1 1} \\
(-0.33,0.11)\end{array}$ & 0.06 & 0.13 \\
\hline $\begin{array}{l}\text { HDL cholesterol } \\
(\mathrm{mmol} / \mathrm{L})\end{array}$ & $1.31(0.23)$ & $1.34(0.23)$ & $\begin{array}{c}\mathbf{0 . 0 2} \\
(-0.07,0.11)\end{array}$ & $1.29(0.41)$ & $1.24(0.40)$ & $\begin{array}{c}-0.06 \\
(-0.13,0.02)\end{array}$ & $1.25(0.34)$ & $1.23(0.40)$ & $\begin{array}{c}-0.02 \\
(-0.07,0.02)\end{array}$ & 0.26 & 0.40 \\
\hline Triglyceride (mmol/L) ${ }^{b}$ & $\begin{array}{c}1.93 \\
(1.45,2.44)\end{array}$ & $\begin{array}{c}1.92 \\
(1.51,2.43)\end{array}$ & $\begin{array}{c}1.00 \\
(0.86,1.16)\end{array}$ & $\begin{array}{c}1.85 \\
(1.34,2.40)\end{array}$ & $\begin{array}{c}1.71 \\
(1.10,1.45)\end{array}$ & $\begin{array}{c}\mathbf{0 . 9 2} \\
(0.82,1.04)\end{array}$ & $\begin{array}{c}1.70 \\
(1.25,2.25)\end{array}$ & $\begin{array}{c}1.62 \\
(1.06,2.38)\end{array}$ & $\begin{array}{c}0.95 \\
(0.82,1.11)\end{array}$ & 0.74 & 0.71 \\
\hline $\begin{array}{l}\text { Total:HDL cholesterol } \\
\text { ratio }^{\text {b }}\end{array}$ & $\begin{array}{c}4.19 \\
(3.36,4.85)\end{array}$ & $\begin{array}{c}4.28 \\
(3.58,5.02)\end{array}$ & $\begin{array}{c}1.02 \\
(0.95,1.09)\end{array}$ & $\begin{array}{c}4.32 \\
(3.83,5.30)\end{array}$ & $\begin{array}{c}4.25 \\
(3.64,4.85)\end{array}$ & $\begin{array}{c}0.98 \\
(0.91,1.06)\end{array}$ & $\begin{array}{c}4.53 \\
(3.51,5.78)\end{array}$ & $\begin{array}{c}4.57 \\
(3.51,5.86)\end{array}$ & $\begin{array}{c}1.01 \\
(0.95,1.07)\end{array}$ & 0.74 & 0.90 \\
\hline
\end{tabular}

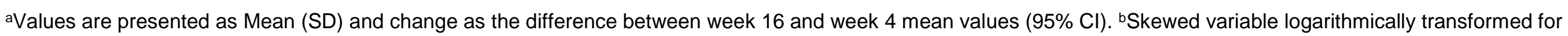

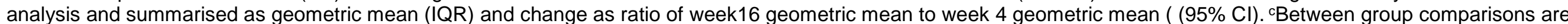
made using one-way analysis of variance and dest for linear trend. FV = Fruit and Vegetables. 
Table 3: Mean change in summary retinal vessel diameters measured in response to a 12 week Fruit and Vegetable (FV) intervention

\begin{tabular}{|c|c|c|c|c|c|c|c|c|c|c|}
\hline \multirow[b]{2}{*}{$\begin{array}{l}\text { Retinal vessel } \\
\text { diameter } \\
\text { measurement } \\
(\mu \mathrm{m})\end{array}$} & \multicolumn{3}{|c|}{ Unadjusted Mean Change $(95 \% \mathrm{Cl})^{\mathrm{a}}$} & \multirow{2}{*}{$\begin{array}{l}\text { Between } \\
\text { group } P \text { - } \\
\text { value }^{b}\end{array}$} & \multirow{2}{*}{$\begin{array}{c}P- \\
\text { Trend }^{c}\end{array}$} & \multicolumn{4}{|c|}{ Adjusted Mean Change $(95 \% \mathrm{Cl})^{d}$} & \multirow[t]{2}{*}{ P-Trend ${ }^{f}$} \\
\hline & $\begin{array}{l}2 \text { portions } \\
\text { FV/day } \\
(\mathrm{n}=20)\end{array}$ & $\begin{array}{c}4 \text { portions } \\
\text { FV/day } \\
(n=20)\end{array}$ & $\begin{array}{c}7 \text { portions } \\
\text { FV/day } \\
(\mathrm{n}=22)\end{array}$ & & & $\begin{array}{c}4 \vee 2 \\
\text { portions } \\
F V / d a y\end{array}$ & $\begin{array}{c}P- \\
\text { value }^{\mathrm{e}}\end{array}$ & $\begin{array}{c}7 \vee 2 \\
\text { portions } \\
\text { FV/day }\end{array}$ & $\begin{array}{c}P- \\
\text { value }^{\mathrm{e}}\end{array}$ & \\
\hline CRAE & $\begin{array}{c}2.4 \\
(-4.4,9.2)\end{array}$ & $\begin{array}{c}1.3 \\
(-6.1,8.6)\end{array}$ & $\begin{array}{c}2.9 \\
(-4.3,10.1)\end{array}$ & 0.94 & 0.92 & $\begin{array}{c}-1.8 \\
(-11.9,8.2)\end{array}$ & 0.71 & $\begin{array}{c}2.4 \\
(-7.6,12.3)\end{array}$ & 0.64 & 0.64 \\
\hline CRVE & $\begin{array}{c}7.5 \\
(-0.2,15.3)\end{array}$ & $\begin{array}{c}1.1 \\
(-8.1,10.3)\end{array}$ & $\begin{array}{c}3.0 \\
(-4.5,10.4)\end{array}$ & 0.50 & 0.42 & $\begin{array}{c}-9.3 \\
(-20.2,1.7)\end{array}$ & 0.10 & $\begin{array}{c}-4.0 \\
(-15.0,6.9)\end{array}$ & 0.46 & 0.25 \\
\hline
\end{tabular}

aVariable summarised as mean change $(95 \% \mathrm{Cl})$ between week 4 and week 16 values, ${ }^{\mathrm{b}}$ Between-group comparisons analysed using one-way analysis of variance and with a ctest for linear trend, ${ }^{d}$ Mean change in retinal vessel diameters adjusted for baseline covariates (age (y), gender (male/female), systolic blood pressure (mmHg) and smoking status (yes/no) and compared using analysis of variance e and with a test for linear trendf. CRAE = Central Retinal Arteriole Equivalent; CRVE = Central Retinal Venule Equivalent; FV = Fruit and Vegetables; 1 portion=80g. 
Table 4: Analysis of covariance to compare post-intervention (week 16) retinal vessel caliber (CRAE/CRVE) adjusting for baseline covariates.

\begin{tabular}{|c|c|c|c|c|}
\hline \multirow[b]{2}{*}{ Baseline Covariate (week 4) } & \multicolumn{2}{|c|}{ Post-intervention CRAE ( $\mu \mathrm{m})$} & \multicolumn{2}{|c|}{ Post-intervention CRVE ( $\mu \mathrm{m})$} \\
\hline & Coefficient (95\% Cl) & p-value & Coefficient (95\% Cl) & p-value \\
\hline FV intake & & & & \\
\hline 4 v 2 (portions/day) & $-1.1(-10.1,7.9)$ & 0.81 & $-4.2(-13.8,5.4)$ & 0.38 \\
\hline 7 v 2 (portions/day) & $1.1(-7.8,10.1)$ & 0.80 & $-0.5(-9.9,8.9)$ & 0.91 \\
\hline CRAE $(\mu \mathrm{m})$ & $0.5(0.2,0.8)$ & $=0.001^{\star *}$ & - & - \\
\hline CRVE $(\mu \mathrm{m})$ & - & - & $0.6(0.4,0.8)$ & $<0.001 * *$ \\
\hline Age (per year) & $0.6(-0.1,1.2)$ & 0.08 & $0.9(0.3,1.6)$ & $0.004^{\star \star}$ \\
\hline Systolic blood pressure (per $\mathrm{mmHg}$ ) & $-0.4(-0.8,0.0)$ & $0.03^{*}$ & $-0.2(-0.6,0.2)$ & 0.28 \\
\hline Gender (male v female) & $-5.8(-13.8,2.1)$ & 0.15 & $0.6(-7.7,8.9)$ & 0.88 \\
\hline Smoking (yes v no) & $-0.9(-11.8,10.1)$ & 0.87 & $-7.0(-18.4,4.4)$ & 0.23 \\
\hline
\end{tabular}

